\title{
From Transactions to Interactions: Social Considerations for Digital Money
}

\author{
Jennifer Ferreira and Mark Perry
}

\begin{abstract}
In our highly connected world, the number of digital transactions is growing, and so too are the myriad of digital platforms that enable these transactions. While the dominant perspective on developing digital payment platforms involves implementing an efficient, low cost, and secure transfer of value, in this chapter, we take a step back to re-examine how digital transactions are embedded in social relationships, and that by focusing solely on the transfer of value, it is possible to miss opportunities for social interactions in digital transactions. We examine the affordances of digital transactions to illustrate possibilities for action, opportunities for interaction, and the roles of negotiation and intermediation within digital transactions. We then highlight some social impacts of digital transactions and its associated data generation, its embeddedness alongside other available forms of transaction, and the ways in which the digital world conflates money with payment systems.
\end{abstract}

\footnotetext{
J. Ferreira $(\bowtie)$

University College Cork, Cork, Ireland e-mail: jferreira@gmx.com
}

M. Perry

Brunel University London, London, UK e-mail: mark.perry@brunel.ac.uk

(C) The Author(s) 2019

T. Lynn et al. (eds.), Disrupting Finance, Palgrave Studies in Digital Business \& Enabling Technologies, https://doi.org/10.1007/978-3-030-02330-0_8 
Keywords Digital money - Financial affordance - Social transactions • Interaction design - User experience design

\subsection{InTRODUCTION}

In standard economic texts, money is usually referred to as a unit of account, a store of value, and a medium of exchange (Asmundson and Oner 2012), and yet when examined as a social phenomenon, other critically important attributes about our societies are revealed, most notably, how trust (Ingham 2004) and power structures (Baker 1987) are operationalised. This view that money's extraeconomic, social basis (Zelizer 2011) should be acknowledged is one that carries increasing weight: the usefulness and value of money-and its concomitant forms of exchange-are socially constructed and locally contingent. Indeed, Simmel's classic text on the philosophy of money (Simmel 1900), in which he examines the mechanisms that underpin economic exchange, considers financial transactions as a form of social interaction and adds that outside the exchange relation, money loses meaning. Dodd upholds a similar view of the inseparability of money and social relations: "[... ] money is a process, not a thing, whose value derives from the dynamic, ever-changing, and often contested social relations that sustain its circulation" (Dodd 2014, Preface). This view allows us to move beyond the abstract, a socialised flow of value that are typical of the literature in economics (Zelizer 2011).

While we are seeing a resurgence in how the use of money is understood, at a practical level, this is being challenged by the move towards making money digital. For technology developers and the banking industry, money appears to be envisaged simply as aseptic, standardised data in binary form, viewed as an online resource, with payment promoted as an efficient form of value token transaction as it moves across digital networks and is audited via a remote banking ledger (Wandhöfer 2017). We argue that this view is not wrong, but that it is a very partial perspective. Nevertheless, it is worth summarising the reasons for this orientation towards money as data so that we can explore its drivers and then begin to dissect how this may limit a discourse about its design and use. It is evident that connected ubiquitous mobile technologies have opened up opportunities for innovative financial technology solutions for storing money and payment instruments (e.g. digital wallets), and 
conducting transactions (e.g. Apple Pay, Square, Stripe). The benefits of transacting digitally, in large part lies in the speed with which identities can be verified and transactions confirmed. Digital payments (see Chapter 7) are considered to be a cheaper form of transaction, and it is estimated that the use of cash can cost countries more than $1 \%$ of their Gross Domestic Product (GDP) (Denecker et al. 2013); electronic payment systems have lower administrative costs, lower security costs, and digital money does not require transportation, so that such reduced digital infrastructural overheads offer considerable advantages. So there is a reasonable argument to be made for considering the value of financial digitalisation as presenting efficiency gains with faster, cheaper, and more mobile transactions. Yet, as we have argued, this ignores aspects of money that are pervasive even in quantitative fields such as economics in which the use of money (through prices) provides information about markets, so that money necessarily involves interactions, not just transactions. So how do we account for the social aspects around transactions? Returning to the conceptualisation of financial transactions embedded in social relations, we investigate where opportunities are for social interactions in digital transactions.

In this chapter, we examine the affordances of digital transactions to illustrate possibilities for action, opportunities for interaction, and the roles of negotiation and intermediation within digital transactions. We then highlight some social impacts of digital transactions and its associated data generation, its embeddedness alongside other available forms of transaction, and the ways in which the digital world conflates money with payment systems.

\subsection{Affordances of Digital Money}

How money is designed lends itself to different forms of use, both physically and socially, and we refer to these forms of use as affordances. Norman (1999, p. 39) explains that "the word affordance was coined by the perceptual psychologist J. J. Gibson (1977) to refer to the actionable properties between the world and an actor (a person or animal)." Similarly, how money is represented shapes the ways in which we can interact with it and use it. Different materials offer different affordances and 'forcing functions' (i.e. constraints on use; Norman 1999), historically illustrated by Jevons from classical literature, noting "there was a tradition in Greece that Lycurgus obliged the Lacedæmonians to use iron 
money, in order that its weight might deter them from overmuch trading" (Jevons 1876, p. 53). These notions of portability designed into the currency would seem to have had a direct impact on use, much in the same way that certain configurations of digital money and payment operations might confer financial benefits around Anti Money Laundering (AML) or Know Your Customer (KYC) regulations, or tracking data on user spending or income might, for example, allow different forms of social sharing, customised marketing, preferential interest rates, or personalised financial services to be made available to users. Here we list some of the affordances of digital money and the opportunities for digital value transfer:

Frictionless: Digital money offers the promise of frictionless transactions. That is, financial interactions that are fast and easy, enabled by contactless technologies. For example, checkout terminals supporting contactless payments are becoming increasingly ubiquitous, where payment simply requires the consumer to wave a card or device in front of a reader, eliminating the need for entering a PIN or swiping a card through the machine. Likewise, but offering a different set of social affordances, Alipay in China supports the use of personalised QR codes, where payment is completed with a scan of the $\mathrm{QR}$ code. But even these forms of directly replacing the traditional form of payment are being challenged as digital technology can reformat the nature of the transaction dramatically. Thus, using a combination of computer vision, sensor fusion, and deep learning with a mobile app, Amazon Go stores eliminate the need for consumers to pass through a checkout point altogether, and therefore eliminate the need for any interaction on the part of the consumer. Described as 'grab-and-go,' the transaction is frictionless in that it is fully automated-consumers enter the store, select their items and then leave. Giving users a means of making sense of how this works, when it is operational, and which payment system is currently operating will be a significant challenge in order to ensure user understanding and trust.

Anonymous: Digital money offers new possibilities for conducting transactions anonymously. Persisting weaknesses in Internet security and privacy concerns drive the need for technological solutions that protect consumers' identities (Juang 2003). One early example of an attempt at an anonymous payment system was e-cash, invented by David Chaum, as a type of limited-traceability system (Chaum 1983; Chaum and Brands 1997). The aim was to emulate the anonymity of cash transactions, through cryptographic protocols (Goldberg et al. 1997). 
Bitcoin, currently the most widely known cryptocurrency, is often cited as an anonymous currency, but it is in fact pseudonymous (Anonymous 2017). Full anonymity, requires hiding not only the identities of those involved in the transaction, but also the content of the transaction as well as metadata such as the date of transaction and method of payment. Further, anonymity in transactions tends to be traded off against speed and requires high levels of processing power. Achieving fully anonymous digital transactions is still an ongoing challenge, and the socio-political value that payment anonymity holds is a topic of contentious debate. Anonymous - and partially anonymous - payments can be problematic in the context of customer service: showing that something has been paid for by a customer (e.g. for item pickup or returns) when it is unclear who has paid is likely to present difficulties when these scenarios are not actively considered by designers.

Transparent: Digital money offers mechanisms for transparency in financial transactions. Blockchain technology (see Chapter 10), popularised by Bitcoin "[..] offers a way of recording transactions or any digital interaction in a way that is designed to be secure, transparent, highly resistant to outages, auditable, and efficient" (Schatsky and Muraskin 2015). Transparency around transactions allows auditing, gauging who you are transacting with, and can help build trust and discourage fraudulent transactions. While this enables an "unprecedented level of forensic analysis to be carried out on the transactions themselves" (Buenaventura 2017, p. 26), it also allows the transactional metadata to be used by other parties, which might include banks, third-party financial services, government agencies and tax authorities, or even users themselves in exploring their patterns of spending. Herein lies a challenge for designers in determining how transparency is managed, and who has access to what information. To what extent would you like others to know your financial arrangements in the same way that Google, Facebook, and Amazon know about your digital existence: Your partner? Your boss? Your bank? Your life or health insurance company? The government? Permissioned transparency also potentially offers criminals access through a backdoor to users' financial records.

Non-denominated: Digital money is divisible in ways that physical money is not. The use of digital money allows micropayments; payments that may even be below normal minimum denominations of currency (e.g. sub-cent or sub-penny). This is made more plausible when transaction charges are low, which enable payments in very small amounts to 
be made viable. Early instantiations of micropayment systems faltered in the 1990s, but blockchain technology, with its potential for lowtransaction cost micropayments offers credible opportunities for casual and ad hoc payments. This has been demonstrated as having value in thing-to-thing (also known as machine-to-machine) payments in the Internet of things (Lundqvist et al. 2017), for example, to purchase or sell power, bandwidth, or data. The effort of making or setting up multiple tiny payments manually, is however, a challenge, and allowing end users (i.e. ordinary citizens) to set these payments up, to monitor them over time, and to ensure that fraudulent payments are not being made requires user interface designs that are easily understandable and simple to operate.

Dataful: Using digital money itself generates data, in a way that using cash does not. This data has enormous potential value and can be used to both generate revenue with new business models, as well as to provide the users themselves with information about their monetary activities, in the same way that Google gains knowledge through users' search activities at the same time as users can gain access to more personalised knowledge as they do so.

\subsection{Opportunities For InTERAction}

For money use to be conceived as social interactions, rather than just transactions, hinges on identifying the opportunities available for money users to engage in social encounters with each other. In the following sections, we draw attention to where these opportunities might be in the transaction, the effects of intermediation on these opportunities, and implications for understanding value in the transaction.

\subsubsection{Negotiating Payment}

Two parties coming to agreement on how payment will proceed, what information will be exchanged and how. While a typical cash transaction occurs during a face-to-face exchange of cash, it is easy to imagine any means of exchange using similar physical formats of money. As one example, one party could place their money in a physical location and hand the other party a set of instructions for how to locate it. The mechanics we choose to adhere to during the exchange of money in our everyday lives are guided by social conventions (Carruthers 2010), but 
not limited to them. Consequently, the rules for the exchange of physical money can be considered negotiable by the transacting parties and, hence, become opportunities for interaction.

\subsubsection{Effects of Intermediation}

The more the transaction is intermediated (by banks, financial institutions, technology, and infrastructure companies), the less choice transacting parties have in setting the rules of the value transfer. For example, a payment involving a bank deposit, will heed the rules as set by the bank and the regulatory framework in which the bank operates. Negotiable matters between the transacting parties are mostly limited to nonprocedural decisions such as the agreement that bank deposit money is a valid form of payment and which banks may be involved. When payments involve digital money, the tools used in the transfer of digital money, and by implication the designers of those tools, further constrain which decisions are left to transacting parties concerning the rules of the value transfer.

\subsubsection{Collaborative Value Creation}

During a transaction, the value is not only something that is transferred between transactors, it can also be created by virtue of the interaction between the transacting parties (Carroll and Bellotti 2015). When people (and devices) have to work together, that is, purposefully coordinate their actions to accomplish a monetary transaction, these transactors are engaging in what has been found to be a valuable set of opportunities for building social connections (Ferreira et al. 2015). In this way, transactors are creating value in the exchange that extends beyond its economic value. Research into cumbersome transactions, that is, transactions that are perceived as slow or tedious, has highlighted the ways in which people engage with each other during the transaction and the implications of this type of interaction for enriching their social relationships. Bringing digital payment devices, such as mobile phones, into the exchange sets up the interactions with yet more potential variations.

What this would suggest is that the payments technology used-infrastructure, interaction design, and physical form factor-offer ways of creating new connections between people and new ways of using money to drive social interactions. 


\subsection{Social Impacts of Digital Transactions}

Along with recognising the opportunities for social encounters in transactions, there is a need to examine the social impacts brought on by transacting digitally. In this section, we present our observations on social impacts with respect to attitudes around financial data, the availability of different forms of money, and understanding of money and payment systems.

\subsubsection{Sensitive Data Generation and Sharing}

Financial and credit card data have been shown to be considered the most sensitive personal data (Rose et al. 2013) and Experian cyber analysts estimate the value of stolen financial data to be worth up to USD 200 on the Dark Web (Stack 2018). In order to protect financial data, laws and regulations have emerged that impose strict security requirements on the institutions and other financial service providers that process financial data. As a result, there are limitations on how financial data can be shared or opened up for inspection. In Europe, there have been moves to allowing third parties (in practice, new FinTech entrants being allowed banking) permissioned access. This poses challenges for new entrants to the FinTech space where no or limited access to data requires creative workarounds in the design of technologies that interface with financial infrastructures.

\subsubsection{Choice Proliferation}

Despite the drive towards cashless societies, digital money and digital exchange continue to co-exist alongside non-digital forms of money and non-digital forms of exchange. Increasingly, the money we use and the ways in which it is exchanged are understood to be a collection of pragmatic responses to wide-ranging needs. So despite governmental and regulatory attempts at homogenising the money system, the varieties of uses and social contexts that emerge around money continue to engender new forms of money and exchange. For example, loyalty points, and volunteer currencies such as time dollars. The proliferation of connected digital tools that enable new forms.

An integrated approach to parallel physical and digital media seems to be a prevalent concern across fiat and alternative currencies 
(see, for example, the Bristol and Brixton Pounds-Perry and Ferreira 2018). Similarly, O'Neill et al. (2017) discuss the challenges and user practices around working digital money into the cash economy; these are non-trivial problems for users in making money work for them, in their individual and local circumstances. Moreover, the physical work that goes into making digital transactions also presents a considerable challenge to designers as they look to develop useful affordances into digital forms of money.

\subsubsection{Untangling Money and Payment System}

When we talk about digital payment systems, or refer to digital or mobile money, we refer not to money as an object of value itself, but to our use of the digital infrastructure that has been built up around the intermediated transfer of value using bank deposit money. This, along with the limited scope for ordinary people to negotiate their own rules around digital payment systems, invites a confusing situation where 'money' and 'payment system' become increasingly difficult concepts to separate in the digital world. In the world of cryptocurrencies, this is taken a step further, with the payment system (as a digitally held ledger of balances) wholly superseding the need for an object-we might call this money-itself. Here, as with a card payment or bank transfer, no actual thing is transferred, but merely a digital record is updated. In this respect, the payment system-the financial infrastructure-takes on the role of money. However, this is very much at odds with the ways that most everyday users of money tend to conceive of its operation when they make or receive payments. The phrase "I'll pay you" is very much an active process of transfer, compared to the reality of transactional settlement that might be functionally better expressed as "I'll initiate a permissioned record change to your bank account." Moreover, there is often very little directness to this financial transfer, with a variety of intermediaries sitting between payer and payee, to the extent that actual financial settlements between the payer and payee's banks may only happen at a single point as an aggregate of all customer transactions between institutions over the accounting time period. When designing payment systems for customers, it may therefore be necessary to represent what actually happens in ways that map more to user perceptions of this process than to institutional actuality. 


\subsection{Conclusion}

Money is a multifaceted dynamic concept and our understanding of it is continually challenged and modified by financial innovations. Perhaps due to a long tradition within monetary theory of treating money as 'neutral,' there is still no agreed position on what money is and, despite ongoing critique, the 'textbook triad' of money as a unit of account, a store of value and a medium of exchange, continues to structure much of the discussion. This difficulty carries over to discussions of digital money and digital transactions. Understanding its use and working to change its operation is an especially complex task precisely because money is so pervasively connected to our lives.

In this chapter, we examined the affordances of digital transactions to illustrate possibilities for action, opportunities for interaction, and the roles of negotiation and intermediation within digital transactions. We have highlighted some social impacts of digital transactions and its associated data generation, its embeddedness alongside other available forms of transaction, and the ways in which the digital world conflate money and payment systems.

As digital money plays an increasingly central role in our lives, having the means to articulate our interactions with it helps to ensure digital transactions are designed to be the kinds of experiences we wish to have. Payment platforms, like any other digital tools, are open to be shaped by their designers, and can do more to support the interactional and transactional work required-future systems that attend to their users' needs offer opportunities that extend far beyond the rather limited current notions of faster payments and cheaper services.

\section{REFERENCES}

Anonymous. (2017, August 23). Bitcoin transactions aren't as anonymous as everyone hoped. MIT Technology Review. Available at: https://www. technologyreview.com/s/608716/bitcoin-transactions-arent-as-anonymous-as-everyone-hoped. Last accessed 19 July 2018.

Asmundson, I., \& Oner, C. (2012). What is money? Finance \& Development, 49(3). Available at: http://www.imf.org/external/pubs/ft/fandd/2012/09/ basics.htm. Last accessed 14 May 2018.

Baker, W. E. (1987). What is money? A social structural interpretation. In M. S. Mizruchi \& M. Schwartz (Eds.), Intercorporate relations (pp. 109-144). Cambridge, MA: Cambridge University Press. 
Buenaventura, L. (2017). Reinventing remittances with Bitcoin. Singapore: Bloom Solutions.

Carroll, J. M., \& Bellotti, V. (2015). Creating value together: The emerging design space of peer-to-peer currency and exchange. In Proceedings of the 18th ACM Conference on Computer Supported Cooperative Work \& Social Computing (CSCW '15) (pp. 1500-1510). New York, NY: ACM.

Carruthers, B. G. (2010). The meanings of money: A sociological perspective. Theoretical Inquiries in Law, 11(1), 51-74.

Chaum, D. (1983). Blind signatures for untraceable payments. In D. Chaum, R. L. Rivest, \& A. T. Sherman (Eds.), Advances in cryptology. Boston, MA: Springer.

Chaum, D., \& Brands, S. (1997). Minting' electronic cash. IEEE Spectrum, $34(2), 30-34$.

Denecker, O., Istace, F., \& Niederkorn, M. (2013). Forging a path to payments digitization. McKinsey on Payments, 16, 3-9. Available at: https://www.mckinsey.com/ /media/mckinsey/dotcom/client_service/financial\%20services/ latest\%20thinking/payments/mopl6_forging_a_path_to_payments_digitization.ashx. Last accessed 30 July 2018.

Dodd, N. (2014). The social life of money. Princeton: Princeton University Press.

Ferreira, J., Perry, M., \& Subramanian, S. (2015). Spending time with money: From shared values to social connectivity. In Proceedings of the 18th ACM Conference on Computer Supported Cooperative Work \& Social Computing (CSCW'15) (pp. 1222-1234). New York, NY: ACM.

Gibson, J. J. (1977). The theory of affordances. In R. E. Shaw \& J. Bransford (Eds.), Perceiving, acting, and knowing. Hillsdale, NJ: Lawrence Erlbaum Associates.

Goldberg, I., Wagner, D., \& Brewer, E. (1997). Privacy-enhancing technologies for the internet. In Proceedings IEEE COMPCON 97 (pp. 103-109). San Jose, CA: Digest of Papers.

Ingham, G. (2004). The nature of money (1st ed.). Cambridge, UK: Polity Press.

Jevons, W. S. (1876). Money and the mechanism of exchange. New York: D. Appleton and Co. Available at: http://www.econlib.org/library/ YPDBooks/Jevons/jvnMMECover.html. Last accessed 14 May 2018.

Juang, W.-S. (2003). A practical anonymous payment scheme for electronic commerce. Computers \& Mathematics with Applications, 46(12), 1787-1798.

Lundqvist, T., de Blanche, A., \& Andersson, H. R. H. (2017). Thing-to-thing electricity micro payments using blockchain technology (pp. 1-6). 2017 Global Internet of Things Summit (GIoTS), Geneva.

Norman, D. (1999). Affordance, conventions, and design. Interactions, 6(3), 38-41.

O'Neill, J., Dhareshwar, A., \& Muralidhar, S. H. (2017). Working digital money into a cash economy: The collaborative work of loan payment. Computer Supported Cooperative Work, 26(4-6), 733-768. 
Perry, M., \& Ferreira, J. (2018). Moneywork: Practices of use and social interaction around digital and analog money. ACM Transactions on ComputerHuman Interaction (TOCHI), 24(6), 41:1-41:32.

Rose, J., Barton, C., Souza, R., \& Platt, J. (2013). The trust advantage: How to win with big data. Available at: www.bcgperspectives.com/content/articles/ information_technology_strategy_consumer_products_trust_advantage_win_ big_data/. Last accessed 14 May 2018.

Schatsky, D., \& Muraskin, C. (2015). Beyond Bitcoin: Blockchain is coming to disrupt your industry. Deloitte University Press. Available at: https://www2. deloitte.com/insights/us/en/focus/signals-for-strategists/trends-blockchain-bitcoin-security-transparency.html. Last accessed 28 August 2018.

Simmel, G. (1900). A chapter in the philosophy of value (3rd ed., D. Frisby, Ed., T. Bottomore \& D. Frisby, Trans.). Routledge: London.

Stack, B. (2018). Here's how much your personal information is selling for on the dark web. Experian. Available at: https://www.experian.com/blogs/ ask-experian/heres-how-much-your-personal-information-is-selling-for-onthe-dark-web/. Last accessed 30 July 2018.

Wandhöfer, R. (2017). The future of digital retail payments in Europe: A role for central bank issued crypto cash? Digital transformation of the retail payments ecosystem. ECB and Banca d'Italia Joint Conference, 30 November and 1 December 2017, Rome, Italy. Available at: https://www.ecb.europa. eu/pub/conferences/shared/pdf/20171130_ECB_BdI_conference/payments_conference_2017_academic_paper_wandhoefer.pdf. Last accessed 13 May 2018.

Zelizer, V. (2011). Economic lives. Princeton: Princeton University Press. 
Open Access This chapter is licensed under the terms of the Creative Commons Attribution-NonCommercial-NoDerivatives 4.0 International License (http://creativecommons.org/licenses/by-nc-nd/4.0/), which permits any noncommercial use, sharing, distribution and reproduction in any medium or format, as long as you give appropriate credit to the original author(s) and the source, provide a link to the Creative Commons license and indicate if you modified the licensed material. You do not have permission under this license to share adapted material derived from this chapter or parts of it.

The images or other third party material in this chapter are included in the chapter's Creative Commons license, unless indicated otherwise in a credit line to the material. If material is not included in the chapter's Creative Commons license and your intended use is not permitted by statutory regulation or exceeds the permitted use, you will need to obtain permission directly from the copyright holder.

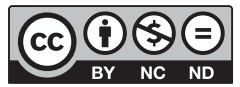

